\title{
Distributions of Dissolved Manganese in the Surface Waters of the Tropical North-Eastern Atlantic Ocean
}

\author{
FARAH AKMAL IDRUS*1,2
}

\begin{abstract}
${ }^{1}$ Department of Aquatic Science, Faculty of Resource Science and Technology, University Malaysia Sarawak, 94300 Kota Samarahan, Sarawak, Malaysia; ${ }^{2}$ National Oceanography Centre of Southampton, University of Southampton, Waterfront Campus, European Way, Southampton SO14 3ZH, UK *Corresponding author: aifarah@unimas.my
\end{abstract}

\begin{abstract}
The tropical North-Eastern Atlantic (TNEA) Ocean region receives high atmospheric input every year, mostly from the Saharan dust and soil. This atmospheric dust and its deposition in the surface ocean are considered to be an important supply of nutrients and trace metal (e.g. dissolved manganese (DMn)) to the euphotic zone of the open ocean regions. Therefore, the objective of this study was to investigate the input of DMn from atmospheric sources and from nearby islands into the TNEA Ocean. A set of surface samples were collected from the Tropical NE Atlantic Ocean, and were analysed for DMn by using the flow injection analyser with chemiluminescence (FIA-CL). Results suggest the land-sources of DMn near to the Canary Islands, the Cape Verde Islands and the African Continent contributed the major inputs of DMn, where high DMn concentrations were determined, with the highest is $3.87 \pm 0.05 \mathrm{nM}$. The lateral advective flux of DMn was higher $\left(47 \mu \mathrm{mol} / \mathrm{m}^{2} / \mathrm{d}\right)$ than the atmospheric flux of DMn $\left(0.17 \mu \mathrm{mol} / \mathrm{m}^{2} / \mathrm{d}\right)$, thus making the shelf and sediment as the most prominent sources of DMn in the seawater close to the islands. From this atmospheric flux of DMn, it was then possible to estimate the DMn enrichment at further offshore dust event regions of $0.73 \mathrm{nM} / \mathrm{yr}$ and consistent with the DMn background concentrations. This support the low residence time calculated in dust event regions of around 1 year. In conclusion, the shelf and sediment are the most prominent DMn sources in the seawater close to the islands and mainland, while in further offshore, the atmospheric inputs are dominant.
\end{abstract}

Keywords: Dissolved manganese, Tropical NE Atlantic Ocean, atmospheric input

\section{INTRODUCTION}

The distributions of DMn in the water column strongly reflect local sources, removal, and recycling processes. In remote ocean regions where there are low Mn inputs, the distribution of DMn are reported to be a scavenged type where the concentrations are depleted at depth relative to surface values. However, Mn distributions can be significantly modified when there are major atmospheric inputs (Statham \& Burton, 1986; Spokes et al., 2001; de Jong et al., 2007), sedimentary inputs from shelf and island systems (Gordon et al., 1998; Bucciarelli et al., 2001; Chase et al., 2005), and local biological activity (may remove manganese). Photochemical reactions can also enhance the concentrations of DMn in surface waters when this particulate $\mathrm{Mn}$ and $\mathrm{Mn}$ oxides are brought to the surface during upwelling or/and vertical mixing; or atmospheric inputs may be photoreduced to the dissolved form, which can be measured using FIA methods (Chase et al., 2005). Removal of DMn may occur by: (1) uptake by the biota (Luengen et al., 2007);
(2) precipitation (Mendez et al., 2010); and (3) scavenging removal of $\mathrm{Mn}$ from dissolved to particulate phases (Statham et al., 1998). Therefore, in productive oceanic systems with high inputs from the atmosphere, shelf, and islands, there are a series of complex interacting processes that influence the biogeochemical cycles of DMn, and one of the factors is the water movement.

In the present study, DMn was determined in seawater samples collected across the TNEA Ocean which receives episodic atmospheric dust inputs from the Sahara Desert. These oceanic waters also contain islands (i.e. Cape Verde and Canary) which can also supply Mn from benthic sources in shallow waters. Therefore, this study was important in improving our understanding of the complex biogeochemistry of DMn in surface waters receiving high atmospheric dust deposition. The objective of this study was to investigate the input of DMn from atmospheric sources and from nearby islands into the TNEA Ocean. 


\section{MATERIALS AND METHODS}

\section{Study Area and Sampling Sites}

TNEA Ocean region receives about a third of global oceanic dust inputs (Jickells \& Spokes, 2001), and most originate from the Sahara Desert. During the UK SOLAS project cruise (D326) in the TNEA Ocean on board RRS Discovery between 5 January and 5 February 2008, 189 underway surface seawater samples were collected for DMn analysis, that started and finished at Santa Cruz, Tenerife (Canary Islands) and covered an oceanic area between $12-27^{\circ} \mathrm{N}$ and $17-36^{\circ} \mathrm{W}$. Underway surface seawater was sampled by pumping it into a trace metal clean container laboratory using a Teflon diaphragm pump (Almatec A-15, Germany) connected by an acid-washed braided PVC tubing to a towed fish positioned at approximately $2 \mathrm{~m}$ depth alongside the ship. The seawater was filtered inline through an acid-washed Sartobran $300 \mathrm{MF}$ $0.2 \mu \mathrm{m}$ filter cartridge, and collected in Nalgene LDPE bottles after being rinsed three times with the seawater sample. There were two dust events during the sampling period, as shown in Figure 1. The underway stations were divided into three regions based on the locations of the dust events, islands, and water masses in the study region as shown in Figure 1: TNEA (north of $\sim 20^{\circ} \mathrm{N}$ ), Cape Verde Islands (CV) $\left(\sim 14-20^{\circ} \mathrm{N}\right)$, and Equatorial (EQ) (below $\sim 14^{\circ} \mathrm{N}$ ).

\section{Chlorophyll $a(\mathrm{Chl}-a)$ and Macronutrients}

Chl- $a$ and macronutrients (nitrate, nitrite, phosphate) were analysed on board the cruise.

\section{Chl-a analysis}

Approximately $200 \mathrm{~mL}$ of seawater sample at each station was filtered onto a Whatman GF/F $25 \mathrm{~mm}$ filter with a pore size $0.7 \mu \mathrm{m}$ following the method from Seeyave et al. (2007). The filters were placed in $20 \mathrm{~mL}$ glass scintillation vials and $10 \mathrm{~mL} \mathrm{90 \%} \mathrm{acetone} \mathrm{(HPLC} \mathrm{grade,} \mathrm{Fisher}$ Chemical) was added for pigment extraction over 24 hours in a dark fridge. Chl- $a$ pigment was measured fluorometrically on board, using a Turner Designs fluorometer following the Welschmeyer (1994) protocol. The fluorometer was calibrated with a chl- $a$ commercial grade standard (Sigma).

\section{Macronutrients analysis}

Analysis for nitrate and nitrite (hereafter write as nitrate+nitrite) and phosphate at nanomolar concentration were measured by, and following a method described in Patey et al. (2008). A segmented-flow auto-analyser with liquid waveguide capillary flow cells each having a two-metre path-length enabled the detection of nanomolar levels of the nutrients. Two tungstenhalogen light sources were used in conjunction with fibre-optic spectrometers to monitor the

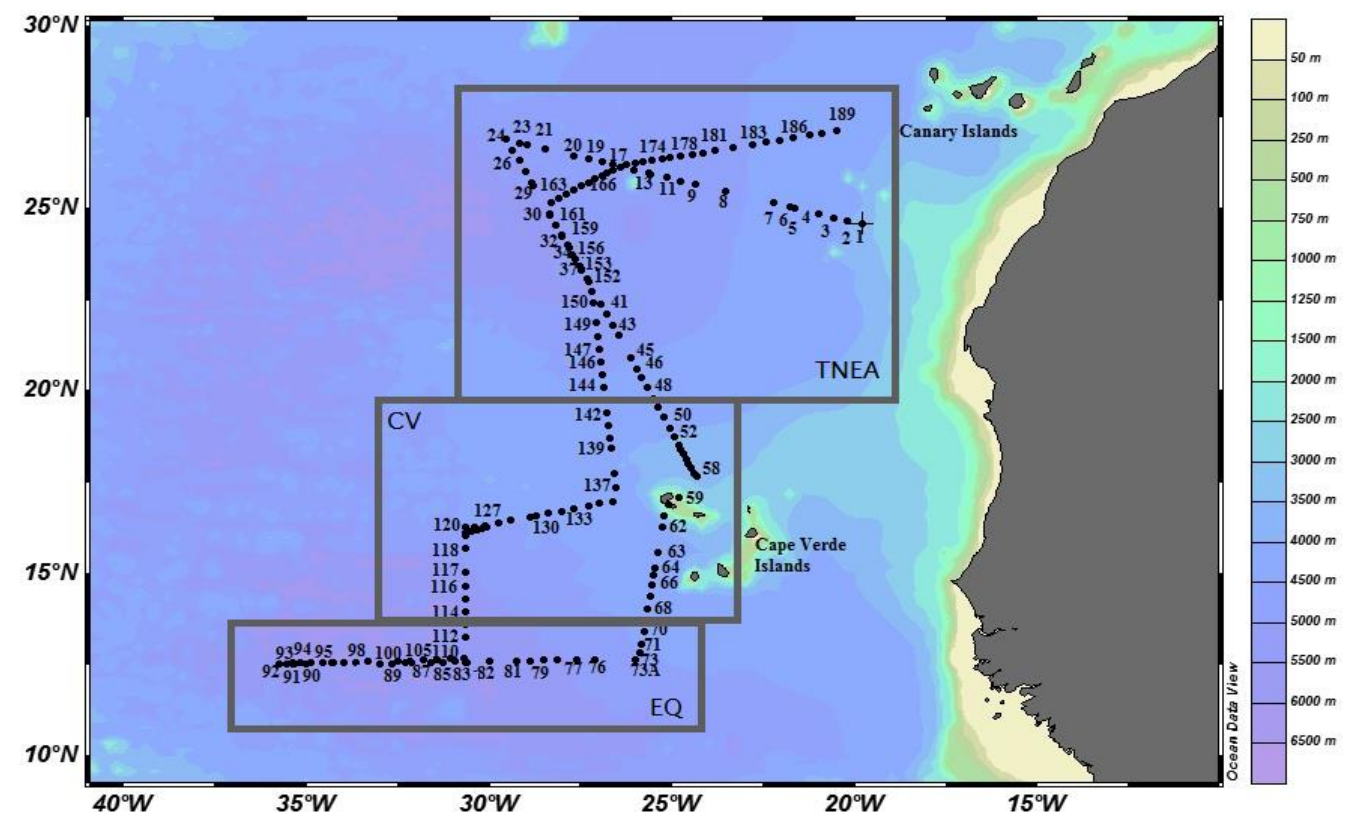

Figure 1. Map of the underway stations sampled for dissolved manganese analysis during D326 in the Tropical NE Atlantic Ocean. The stations were divided into three regions as marked in grey boxes (the first event was in the EQ region and the second event was in the TNEA and CV regions). TNEA: Tropical NE Atlantic; CV: Cape Verde; and EQ: Equatorial. 
absorbance of the solution flowing through the waveguides. Samples were taken in $\mathrm{HCl}$-washed $60 \mathrm{~mL}$ LDPE bottles.

\section{Dissolved Manganese Analysis}

Ruzicka and Hansen (1988) described flow injection analysis (FIA) as an automated method based on injection of a liquid sample into a continuous flow and mixing of suitable carrier solutions (reagents) before transport towards a detector that continuously records the absorbance. DMn was determined using a FIA based on the luminol (5-amino-2,3-dihydro-1,4phthalazinedione) chemiluminescent technique as described in Castrillejo et al. (2013), in which $\mathrm{Mn}$ is initially pre-concentrated onto the Toyopearl $650 \mathrm{AF}$ resin, prior to elution and separation from potentially interfering metal ions using a nitrilotriacetic (NTA) resin and determination using the luminol light-emitting reaction. Samples were individually buffered prior to analysis. Procedural blank was $40 \mathrm{pM}$ with a precision of $20 \mathrm{pM}$. The detection limit (calculated as three times the standard deviation of the blank) was $60 \mathrm{pM}$ with an average relative standard deviation of $11.7 \%$. Accuracy was determined using Certified International Standard Material NASS-5 (National Research Council of Canada) that was processed in the same way as the samples $(16.53 \pm 0.60 \mathrm{nM}$ $(n=4))$.

\section{RESULTS}

\section{Water Masses}

Between $27^{\circ} \mathrm{N}$ (north of Canary Islands) and $12^{\circ} \mathrm{N}$ (south of Cape Verde Islands), the Canary Current flows southward along the African coast at $10-30 \mathrm{cms}^{-1}$, and about $1000 \mathrm{~km}$ wide and $\sim 500$ m deep (Batten et al., 2000; Zhou et al., 2000). To the north of the Cape Verde Islands (north of $13^{\circ} \mathrm{N}$ ), there is the North Equatorial Current (NEC) and Canary Current (CC) (Stramma et al., 2005) characterized by lower temperatures and higher Chl- $a$ concentrations due to the North West African Upwelling (Sarthou et al., 2003). A distinct oxygen minimum zone is positioned south of the NEC and north of the North Equatorial Counter-current (nNECC). In the region of $15^{\circ} \mathrm{N}$, the current diverges westward under the influence of the Equatorial Countercurrent (Peterson et al., 1996). The northern region at $30^{\circ} \mathrm{N}$ is in the subtropical gyre and is characterized by oligotrophic conditions with a deep pycnocline and lower atmospheric dust inputs than the stations close to $10^{\circ} \mathrm{N}$. The $10^{\circ} \mathrm{N}$ site is on the edge of the subtropical gyre and equatorial system, and has a shallow pycnocline and higher dust inputs (Bergquist \& Boyle, 2006). The hydrography around the Canary Islands and Cape Verde Islands themselves are additionally influenced by coastal upwelling, filaments and eddies (Johnson \& Stevens, 2000) (Figure 2).

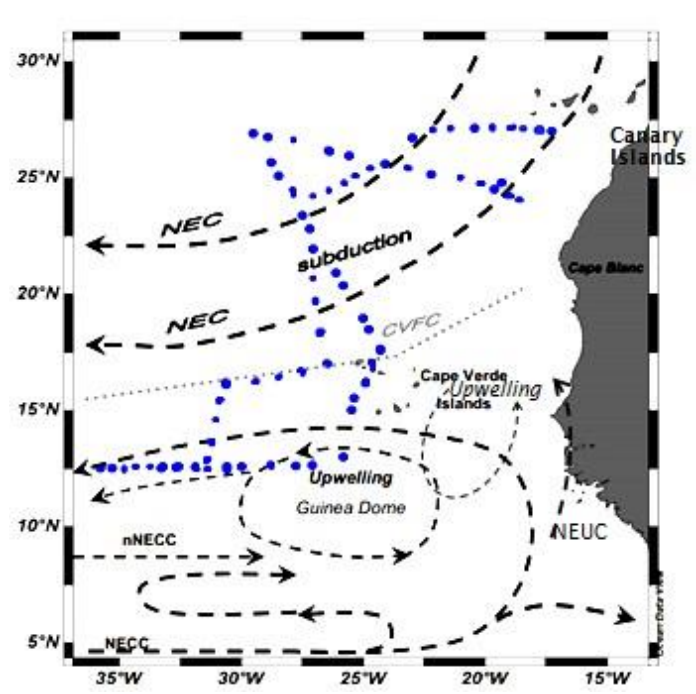

Figure 2. Map of the study area with the cruise track of the RRS Discovery 326 sailed in January-February 2008. The cruise track is shown in the map with dots together with the large scale near-surface flow field described by black-dashed arrows (Stramma et al., 2005). NEC: North Equatorial Current; nNECC: the return flow of the northern North Equatorial Countercurrent; NECC: the north flowing part of the North Equatorial Counter-current which is connected to the NEUC; NEUC: North Equatorial Undercurrent; CVFC: Cape Verde Frontal Zone; and the upwelling regions around the Guinea Dome and Cape Verde Islands. 
Temperature-salinity diagrams for all stations indicated three distinct regions, which have been termed as the TNEA, CV, and EQ regions (Figure 3). The TNEA region had mixed layer depth between 100 and $150 \mathrm{~m}$, with a moderate temperature gradient between upper and lower layers. Warm waters with shallow mixed layers of 35 to $70 \mathrm{~m}$ were evident in the EQ region. A complex surface temperature-salinity pattern was shown in the vicinity of the $\mathrm{CV}$, particularly in the CVFC (Figure 3) where waters around the $\mathrm{CV}$ region received influences from the topography of the CV. Based on these water masses, station numbers $1-48$ and $144-189$ correspond to TNEA, station numbers $49-68$ and $114-143$ correspond to $\mathrm{CV}$, and station numbers $69-113$ correspond to EQ (Figure 3).

\section{DMn, Chl- $a$ and Macronutrients}

The concentrations of DMn, Chl- $a$, nitrate+nitrite, phosphate and residence time of DMn are shown in Table S1. The concentrations of DMn in the surface layer of the TNEA region (Figure 4(a)) were generally below $2 \mathrm{nM}$, with the exceptions of station 1 and station 146 where the concentrations of DMn were above $3 \mathrm{nM}$. Higher DMn concentrations that were observed close to the Canary Islands coincided with higher phosphate concentrations ( 100 nM). However, concentrations of nitrate+nitrite (Figure 4(d)) and Chl- $a$ (Figure 4(b)) were also elevated at this station with $\sim 50 \mathrm{nM}$ and $\sim 0.8$ $\mu \mathrm{g} / \mathrm{L}, \quad$ respectively. These elevated concentrations showed that there were additional inputs of nutrients and $\mathrm{Mn}$ from the Canary Islands and possibly also the African coast, which subsequently increased the Chl- $a$ concentrations. The minimum concentration of the surface Chl- $a(\sim 0.02 \mu \mathrm{g} / \mathrm{L})$ was observed in the TNEA region (station 21) at some distance from the Canary Islands, during the second dust event (Figure 4(b)) where the concentrations of DMn were not uniform due to sporadic inputs from the atmosphere. In areas where there were assumed to have been high dust inputs recently (containing high soluble $\mathrm{Mn}$ ), increased concentrations of DMn (e.g. at station $146(\sim 3$ $\mathrm{nM})$ ) were observed. When the cruise approached the $\mathrm{CV}$, elevated DMn concentrations were observed, coinciding with the increased concentrations of phosphate. In the EQ region, there were variable concentrations of Chl- $a$ during the first dust event that occurred, with highest and lowest concentrations of $\sim 0.6$ $\mu \mathrm{g} / \mathrm{L}$ and $\sim 0.1 \mu \mathrm{g} / \mathrm{L}$ respectively, to give an average concentration of $\sim 0.26 \mu \mathrm{g} / \mathrm{L}$ (Figure 4(b)).

The concentration of Chl- $a$ was at a maximum at station 69, coinciding with low phosphate and DMn concentrations. As the concentrations of Chl- $a$ gradually decreased along the underway stations, the phosphate and DMn concentrations showed an inverse pattern. Phosphate concentrations were enhanced significantly ( $\sim 20$ $\mathrm{nM}$ ) during the first dust event at station 82 and at station 93 to approximately $24 \mathrm{nM}$, corresponding with elevated DMn concentrations at both stations (Figure 4(a)).

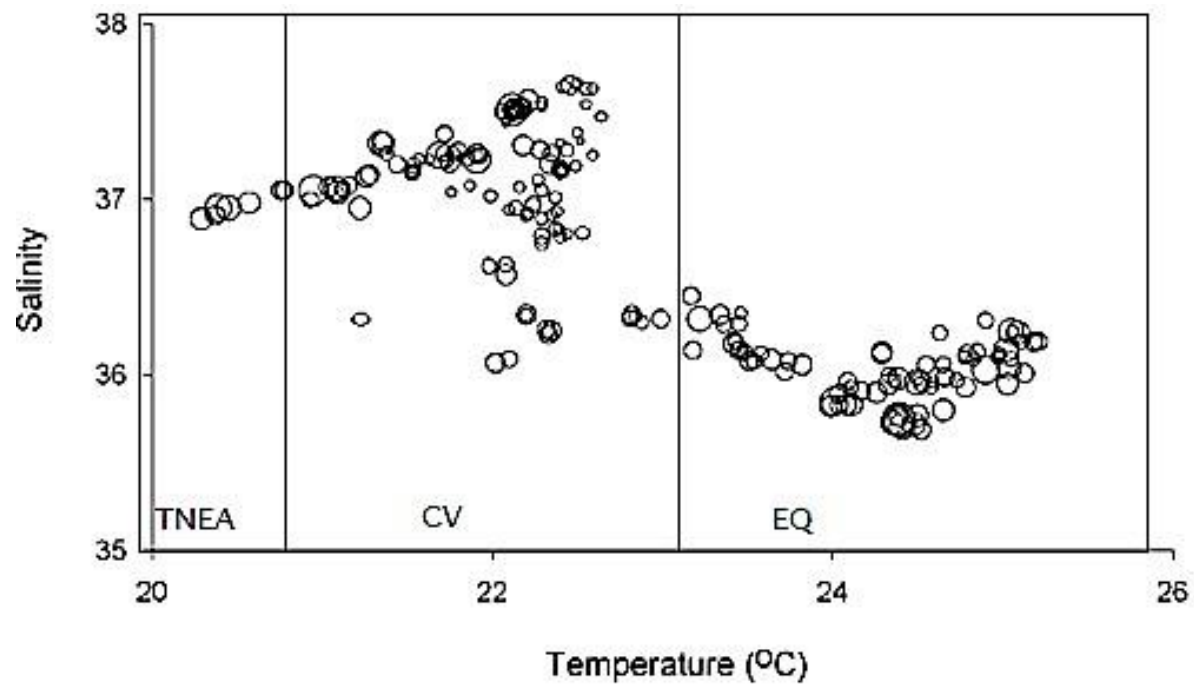

Figure 3. Temperature-salinity plot during the D326 cruise. T-S plot is divided according to three regions: TNEA (Tropical NE Atlantic), CV (Cape Verde), and EQ (Equatorial) regions (adapted from Rijkenberg et al., 2012). 

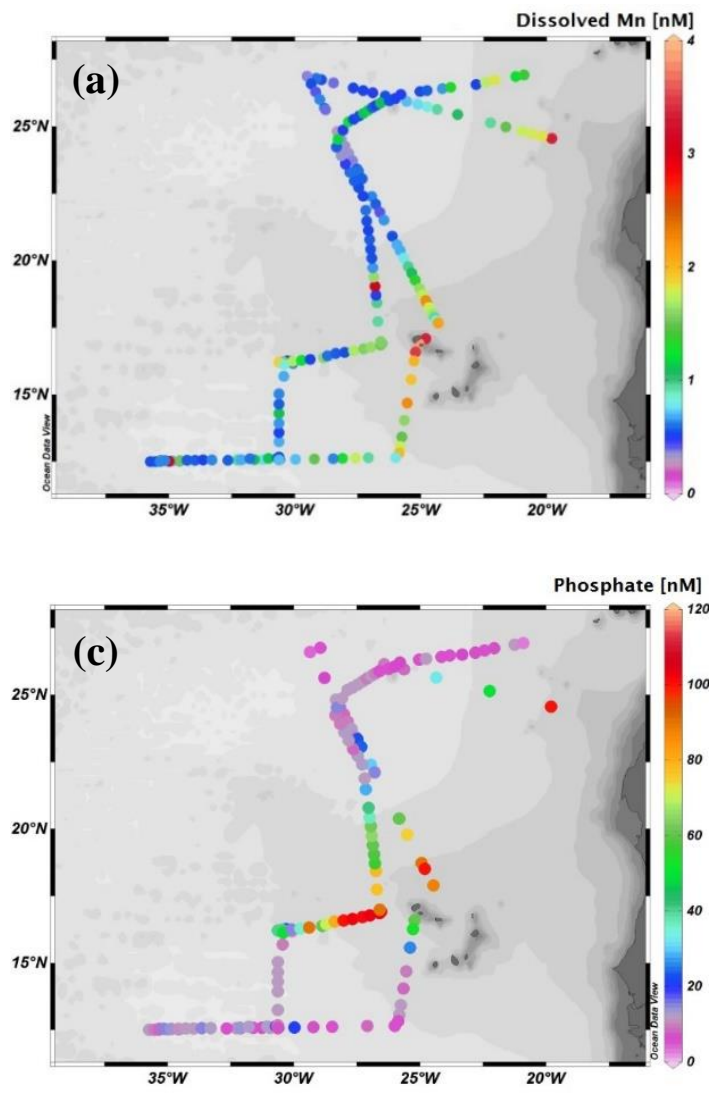
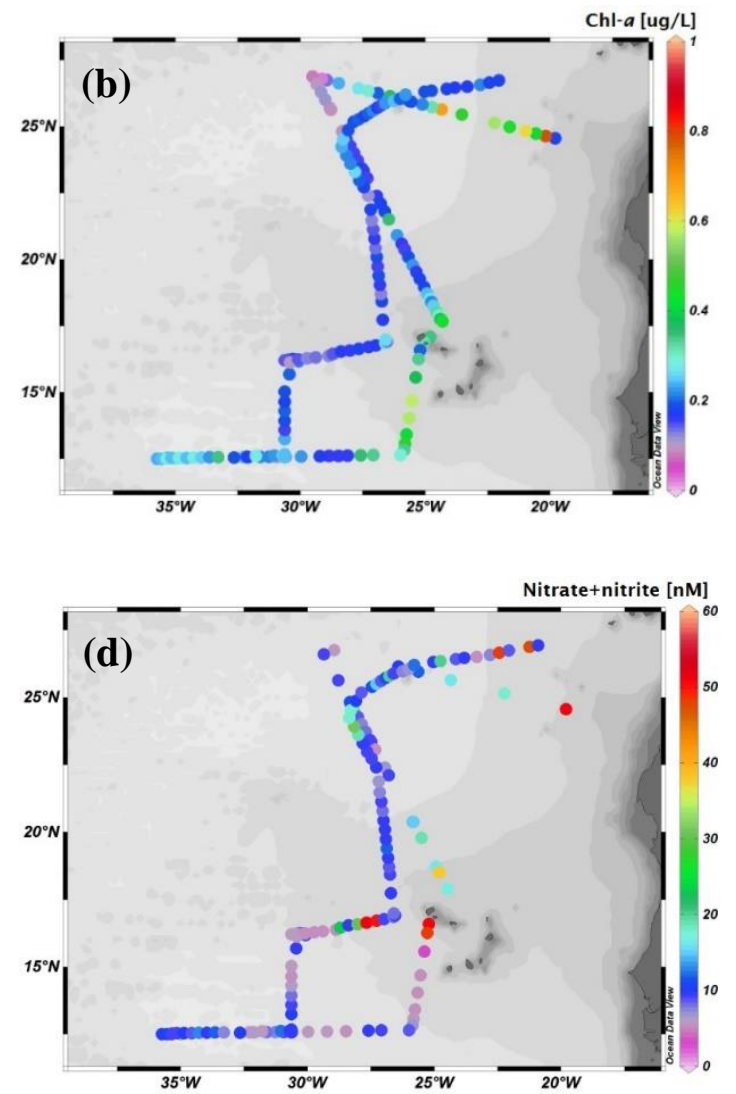

Figure 4. Distributions of surface dissolved manganese (nM) (a), Chl- $a$ concentrations ( $\mu \mathrm{g} / \mathrm{L})(\mathrm{b})$, phosphate concentrations $(\mathrm{nM})(\mathrm{c})$, and nitrate+nitrite concentrations $(\mathrm{nM})(\mathrm{d})$ observed during the UK SOLAS Discovery (cruise D326) in the tropical NE Atlantic Ocean.

However, nitrate+nitrite and Chl- $a$ concentrations were low during the first dust event, with an exception at station 90 where the Chl- $a$ concentration was elevated, when both nitrate and phosphate concentrations were low. Apart from the dust event, these variable concentrations of DMn, Chl- $a$, and major nutrients observed at this region were also influenced by the large scale near-surface currents flow (Figure 2) across this EQ region, such as the NECC, the nNECC and the upwelling around the Guinea Dome. Chl- $a$ and macronutrients are variable depending on bloom development.

In the $\mathrm{CV}$ region, the concentrations of Chl- $a$ were increased up to $\sim 0.6 \mu \mathrm{g} / \mathrm{L}$ (Figure $4(\mathrm{~b})$ ) particularly around the CV. However, the concentrations of Chl- $a$ decreased (until $\sim 0.1$ $\mu \mathrm{g} / \mathrm{L}$ ) during the sampling periods (when the cruise sailed back to the Canary Islands) of the second dust event occurred. The surface concentrations of DMn around the $\mathrm{CV}$ ranged between approximately $0.5 \mathrm{nM}$ and $3.87 \mathrm{nM}$, with an average of $1.41 \pm 0.78 \mathrm{nM}$ (Figure 4(a)).
The observed high DMn concentrations in this region coincided with a complex temperaturesalinity pattern in the vicinity of the CVFZ (Figure 3). The DMn concentrations increased (up to $3.87 \mathrm{nM})$ in the shallow water $(<250 \mathrm{~m}$ ) depth of the CV, coinciding with low Chl- $a$ and nitrate concentrations. In addition to upwelling, there was also input from the atmosphere at this location. Chiapello et al. (1995) observed that the $\mathrm{CV}$ receive maximum dust inputs between November and April as winds direction which transport dusts from the African continent in the trade-wind layer affects only the TNEA Ocean. At station 68, where the highest Chl-a concentration $(\sim 0.6 \mu \mathrm{g} / \mathrm{L})$ of this region was recorded, both major nutrients (phosphate and nitrate+nitrite) concentrations were at minimum (Figure 4(c) \& (d)), and the concentration of DMn was also decreased to approximately 1.6 $\mathrm{nM}$. When the second dust storm started (on $25^{\text {th }}$ January 2008), DMn concentrations were reduced to $\sim 1.09 \mathrm{nM}$ before gradually increasing to approximately $1.90 \mathrm{nM}$. The phosphate concentrations were also following a similar trend, but with significant increases. Enhanced 
phosphate concentrations during the dust events have been observed in the Mediterranean Sea, where aerosols form a crucial source of phosphate to oligotrophic oceans (Rijkenberg et al., 2012).

\section{DISCUSSION}

DMn and associated data (e.g. chl- $a$ concentration, macronutrients, temperature, and salinity) were used to study the biogeochemistry of DMn the surface TNEA Ocean. Overall, DMn concentrations obtained in this study were about double the concentrations observed by de Jong et al. (2007) who found an average value of approximately $0.50 \pm 0.08 \mathrm{nM}$. However, values obtained here were lower than the values determined by Bergquist and Boyle (2006) further offshore in the Tropical and Subtropical Atlantic Ocean, who found an average concentration of $2.60 \pm 0.36 \mathrm{nM}$. Values presented here are in the range of values obtained by Statham et al. (1998) within the range of 0.90$2.12 \mathrm{nM}$ in the NE Atlantic Ocean.

\section{Dust - Potential Source of DMn}

Distributions of Mn in seawater are controlled by a combination of several important factors, particularly the sources of Mn. Atmospheric input is the most important source of $\mathrm{Mn}$ in the open ocean. Modifications of biogeochemical fluxes in surface waters mainly depend on atmospheric inputs, plus photo-reduction and physical processes. However, tracing individual sources of Mn to specific regions is complicated by several factors and really depends on the physical and chemical properties of the waters at the stations. During the research cruise, two significant dust events were noticeable. The first dust event was encountered between 17 and 22 January 2008 (EQ area) and the second dust event (further north) was longer, from 25 January to 1 February 2008.

Dissolved aluminium (DAl) data have been used as a proxy of atmospheric dust deposition in the ocean (Measures \& Vink, 2000). From Al data obtained from this cruise (Patey et al., 2015), estimated atmospheric fluxes of soluble Mn to the TNEA Ocean can be calculated.

Atmospheric deposition occurs by dry (dust) and wet (rain) deposition. However, it is not possible to calculate wet deposition fluxes as there was no rain samples collected during the sampling period. In addition, dry dusts originating from the arid regions of western Africa are associated with very little rainfall, thus it make dry deposition the dominant atmospheric mode of input (Baker et al., 2007). The dust input D $\left(8.55 \mathrm{~g} / \mathrm{m}^{2} / \mathrm{yr}\right)$, was estimated using the Equation 1 below, as described by Measures and Vink (2000) and de Jong et al. (2007):

$$
\begin{array}{r}
\mathrm{D}=\left([\mathrm{DAl}]_{\mathrm{sw}} \mathrm{M}_{\mathrm{Al}} \mathrm{Z}_{\mathrm{mix}} / \tau_{\mathrm{DAl}}\right) /\left(\mathrm{S}_{\mathrm{Al}} \mathrm{A}_{\mathrm{Al}}\right) \\
\text { (Equation 1), }
\end{array}
$$

where $[\mathrm{DAl}]_{\mathrm{sw}}$ is the average concentration of dissolved aluminium in surface seawater (27.53 $\mathrm{nmol} / \mathrm{m}^{3}$, (Patey, 2010)), $\mathrm{M}_{\mathrm{Al}}$ is the atomic weight of aluminium $(26.98 \mathrm{~g} / \mathrm{mol}), Z_{\text {mix }}$ is the mixed layer depth $(90 \mathrm{~m}), \tau_{\text {DAl }}$ is upper ocean residence time of dissolved aluminium (4 year), $\mathrm{S}_{\mathrm{Al}}$ is the Al solubility of Saharan dust $(3.0 \%)$ from Baker et al. (2006), $\mathrm{A}_{\mathrm{Al}}$ is the abundance of $\mathrm{Al}$ in Saharan dust $(6.51 \%$ by weight (Guieu $e t$ al., 2002)).

From the calculated atmospheric dust flux above, the atmospheric flux of manganese was calculated using the Equation 2:

$$
\mathrm{F}_{\mathrm{atm}, \mathrm{TMn}}=\left(\mathrm{D} \mathrm{A}_{\mathrm{Mn}}\right) / \mathrm{M}_{\mathrm{Mn}}
$$

(Equation 2),

where $\mathrm{F}_{\mathrm{atm}}, \mathrm{TMn}$ is the total atmospheric flux (111 $\mu \mathrm{mol} / \mathrm{m}^{2} / \mathrm{yr}$ ) of manganese, $\mathrm{D}$ is dust input (8.55 $\left.\mathrm{g} / \mathrm{m}^{2} / \mathrm{yr}\right), A_{M n}$ is manganese abundance in Saharan dust (0.0712\%, Wedepohl, 1995), $\mathrm{M}_{\mathrm{Mn}}$ is atomic weight of manganese $(54.94 \mathrm{~g} / \mathrm{mol})$.

From the $F_{\text {atm, }}$ TMn value, the dissolved manganese flux $\left(\mathrm{F}_{\mathrm{atm}, \mathrm{DMn}}=61.10 \mu \mathrm{mol} / \mathrm{m}^{2} / \mathrm{yr}\right)$ was calculated after the Equation 3 of de Jong $e t$ al. (2007):

$$
\mathrm{F}_{\mathrm{atm}, \mathrm{DMn}}=\left(\mathrm{S}_{\mathrm{Mn}}\right) \cdot\left(\mathrm{F}_{\mathrm{atm}, \mathrm{TMn}}\right)
$$

(Equation 3),

where $S_{\mathrm{Mn}}$ is solubility for median particle size values for Saharan dust from Baker et al. (2006): Mn 55\% (range 50-64\%).

Therefore, the atmospheric dust deposition flux for soluble manganese in the study region is $0.17 \mu \mathrm{mol} / \mathrm{m}^{2} / \mathrm{d}$. This value is low compared to iron and aluminium values which are approximately $3870 \mu \mathrm{mol} / \mathrm{m}^{2} / \mathrm{d} \quad$ and approximately $140 \mu \mathrm{mol} / \mathrm{m}^{2} / \mathrm{d}$, respectively (Patey, 2010). 


\section{Residence Time of DMn}

Estimation of the residence time of DMn around the study region gives the average time that DMn spends in the surface waters. The residence time of DMn at a steady state can be calculated by using the Equation 4:

$$
\tau_{\mathrm{DMn}}=\left([\mathrm{DMn}]_{\mathrm{obs}} \cdot \mathrm{Z}_{\mathrm{mix}}\right) / \mathrm{F}_{\mathrm{atm}, \mathrm{dMn}}
$$

(Equation 4),

where $\tau_{\mathrm{DMn}}$ is the residence time for $\mathrm{DMn}$, $[\mathrm{DMn}]_{\text {obs }}$ is the measured surface average of DMn concentration (this is assumed to be constant throughout the mixed layer), $\mathrm{Z}_{\text {mix }}$ is the mixed layer depth $(90 \mathrm{~m})$, and $\mathrm{F}_{\mathrm{atm}}$, dMn is the DMn atmospheric flux $\left(61.1 \mu \mathrm{mol} \mathrm{m} \mathrm{m}^{-2} \mathrm{yr}^{-1}\right.$ or $\left.170 \mathrm{nmol} / \mathrm{m}^{2} / \mathrm{d}\right)$. The residence times for individual stations are shown in Table S1, and results are summarized in Table 1.

Overall, average residence time of DMn at these study regions were approximately 1 year and the residence times obtained in this study were slightly shorter than previously estimated, for example, de Jong et al. (2007) estimated a range of $1.0-3.8$ years, with an average of 1.9 year in the NEA Ocean. However, their atmospheric input was low compared to the atmospheric input during this study. The surface concentrations of DMn in this study are also higher than de Jong et al. (2007) values. Therefore, the DMn distributions at the TNEA Ocean and atmospheric sources are more temporally variable than previously thought.

On the repeat transect along the EQ section, the concentrations of DMn were lower than on the outbound leg. However, the concentrations of DMn and dissolved iron (DFe) (Rijkenberg et $a l .$, 2012) were elevated in the surface layer, indicating an atmospheric source of trace metals at these stations. The expected DMn concentrations enrichment in a cubic meter of seawater due to atmospheric inputs can be calculated by using Equation 5:

$$
\text { DMn enrichment }=F_{\text {atm, DMn }} / \text { MLD }
$$

(Equation 5),

where $F_{\text {atm, DMn }}$ is the atmospheric dust deposition flux for soluble $\mathrm{Mn},\left(170 \mathrm{nmol} / \mathrm{m}^{2} / \mathrm{d}\right)$ and MLD is mixed layer depth $(90 \mathrm{~m})$. By putting these values into Equation 5, the concentrations of DMn per $1 \mathrm{~m}^{3}$ (1000L) input around the dust event regions is $0.002 \mathrm{nmol} / \mathrm{L} / \mathrm{d}$, to give approximately $0.73 \mathrm{nmol} / \mathrm{L} / \mathrm{yr}$, which is consistent with the data obtained here (given typical concentration values and a residence time of about 1 year). These values thus supported the low average residence time calculated in dust event regions of around 1 year. Reason for the observed low $\mathrm{Mn}$ values compared to high $\mathrm{Al}$ and $\mathrm{Fe}$ is most likely the large inputs of $\mathrm{Al}$ and $\mathrm{Fe}$ relative to $\mathrm{Mn}$ in this zone.

\section{Islands and Mainland - Potential Sources of DMn}

The relationship between concentrations of DMn adjacent to the African continent, and the distance from the African continent (in $\mathrm{km}$ ) were examined in order to investigate the source of $\mathrm{DMn}$ in the surface layer ocean (adapted from Rijkenberg et al. (2012)).

The distribution of DMn in the TNEA region decreased exponentially with increasing distance from the African continent $\left(\mathrm{R}^{2}=0.897,[\mathrm{DMn}]\right.$ $(\mathrm{nM})=2.812 \mathrm{e}^{-(\mathrm{x})}$, where $\mathrm{x}$ is the distance in $\left.\mathrm{km}\right)$ (Figure 5). However it must be remembered that a part of this signal may originate from the upstream Canary Islands, as well as the African coast.

Table 1. Average of DMn residence times for different regions. The mixed layer depth (MLD) is $90 \mathrm{~m}$, and the atmospheric flux of DMn is $61.10 \mu \mathrm{mol} \mathrm{m}^{-2} \mathrm{yr}^{-1}$.

\begin{tabular}{lc}
\hline \multirow{2}{*}{ Station } & Residence time (years) \\
\cline { 2 - 2 } TNEA region & Average (year) \\
CV region & 0.66 \\
EQ region & 1.14 \\
\hline
\end{tabular}




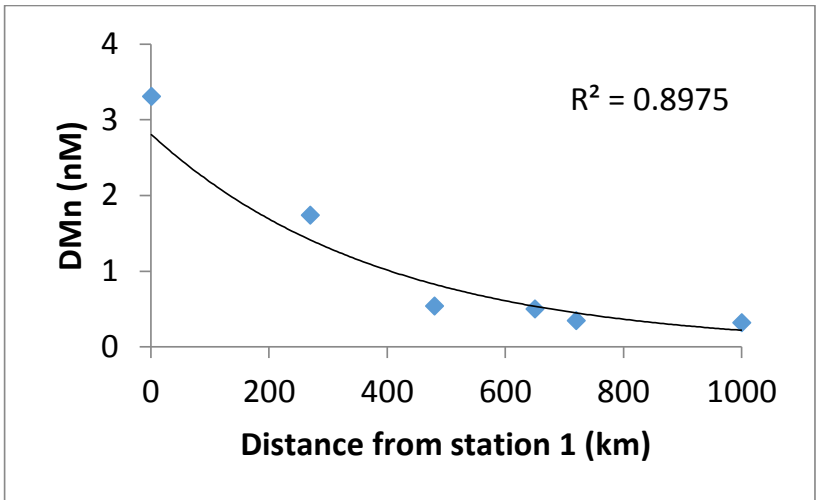

Figure 5. The DMn concentration in the surface layer for stations influenced by Canary Islands and the African continent inputs, and the offshore stations. Station 1 is the closest to the African continental shelf and its x-position is set to $0 \mathrm{~km}$.

The horizontal flux of DMn $\left(\mathrm{F}_{\mathrm{DMn}}\right)$ was calculated using Equation 6:

$$
\mathrm{F}_{\mathrm{DMn}}=\mathrm{C}_{0} \mathrm{e}^{-\mathrm{x} / \mathrm{D}} \quad \text { (Equation 6), }
$$

where $\mathrm{C}_{0}$ is the concentration at station $1, \mathrm{x}$ is the distance $(\mathrm{km})$ from station 1 , and $\mathrm{D}$ is the scale length (451 km, Rijkenberg et al. (2012)). The exponential fit was $[\mathrm{DMn}]=2.812 \mathrm{e}^{-\mathrm{x} / 451}$ (Figure $5)$. Then, the parameterization to estimate lateral diffusion coefficient $\left(\mathrm{K}_{\mathrm{h}}, \mathrm{m}^{2} / \mathrm{s}\right)$ can be calculated by using Equation 7 to give a value of $1.83 \mathrm{~m}^{2} / \mathrm{s}$ :

$$
\mathrm{K}_{\mathrm{h}}=7.3 \times 10^{-4} \mathrm{D}^{0.15} \quad \text { (Equation 7) }
$$

Combining this estimated lateral diffusion coefficient, $\mathrm{K}_{\mathrm{h}}$, with the DMn gradient from near shore to further offshore $\left(\mathrm{DMn}_{\text {gradient }}\right)$, gives a lateral flux of $\mathrm{DMn}\left(\mathrm{DMn}_{h}\right)$ of $47.4 \mu \mathrm{mol} \mathrm{m}^{-2} \mathrm{~d}^{-}$ 1 or $17.3 \mathrm{mmol} \mathrm{m} \mathrm{mr}^{-1}$ (dependent on the coastline length), as calculated in Equation 8:

$$
\begin{gathered}
\mathrm{DMn}_{h}=\mathrm{DMn}_{\text {gradient }} \cdot \mathrm{K}_{\mathrm{h}} \quad(\text { Equation 8) } \\
\mathrm{DMn}_{h}=0.003 \mathrm{nmol} \mathrm{m}^{-3} \mathrm{~m}^{-1} \bullet 1.83 \mathrm{~m}^{2} \mathrm{~s}^{-1} \bullet 3600 \mathrm{~s} \\
\cdot 24=47.4 \mu \mathrm{mol} \mathrm{m} \mathrm{d}^{-1}
\end{gathered}
$$

The decrease in DMn coincided with an increase in DAl (Rijkenberg et al., 2012). Therefore, a continental source of waters rich in DMn but not DAl appears to have influenced the DMn distribution. The source of DMn may either be anoxic shelf sediments (Chase et al., 2005) or the upwelling of deep waters along the continental shelf which may have collected Mn from the shelf on its trajectory. Elevated concentrations of DMn in bottom waters may be due to the release of dissolved forms of $\mathrm{Mn}$ from re-suspended particles and the diffusion from pore waters (Laes et al., 2007). Sediment on the continental shelf may be high in dissolved and particulate $\mathrm{Mn}$ including manganese oxides $\left(\mathrm{MnO}_{\mathrm{x}}\right)$. Particulate $\mathrm{Mn}$ from the sediment can be brought back to the surface water during the upwelling and strong sunlight in the TNEA Ocean can enhance the photo-reduction process which changes the particulate form of Mn to the dissolved form (Chase et al., 2005; Sunda \& Huntsman, 1983).

\section{CONCLUSION}

Relatively low concentrations of DMn were observed during both dust events, suggesting only small inputs. Dust inputs will be episodic, but an estimation of the annual atmospheric flux of DMn was calculated and gave a value of approximately $61 \mu \mathrm{mol} / \mathrm{m}^{2} / \mathrm{yr}$ or about 0.17 $\mu \mathrm{mol} / \mathrm{m}^{2} / \mathrm{d}$, which was low compared to the atmospheric fluxes of DFe and DAl. The residence times obtained from this study were shorter, approximately 1 year, thus suggesting that the DMn distribution in the TNEA Ocean were more temporally variable. Furthermore, DMn enrichments of $0.002 \mathrm{nmol} / \mathrm{L} / \mathrm{d}$ or 0.73 $\mathrm{nmol} / \mathrm{L} / \mathrm{yr}$ were estimated in the seawater around the dust events, which is consistent with the background concentrations of DMn obtained here. Higher surface concentrations of DMn were observed at stations in close proximity of the islands and coastal mainland sources (e.g. the Canary Islands, the $\mathrm{CV}$, and the African continent), up to $\sim 3.90 \mathrm{nM}$. The distribution of DMn decreased with increasing distance away from the land sources (i.e. TNEA region). The 
lateral DMn flux was calculated to give a value of approximately $47 \mu \mathrm{mol} / \mathrm{m}^{2} / \mathrm{d}$ or $\sim 17.3$ $\mathrm{mmol} / \mathrm{m}^{2} / \mathrm{yr}$. However, the atmospheric input estimated for this study were small $(0.17 \mu \mathrm{mol}$ $\mathrm{m}^{-2} \mathrm{~d}^{-1}$ ), thus making the shelf + sediment are the most prominent DMn sources in the seawater close to the islands and mainland, while in further offshore, the atmospheric inputs are dominant.

\section{ACKNOWLEDGEMENTS}

This study was funded by Ministry of Higher Education Malaysia under Academic Training Scheme (SLAI) KPT(BS)830304085190. The author would like to acknowledge Professor Peter Statham for giving opportunity to work on this research. Appreciation also goes to all crews and researchers of the UK SOLAS project (cruise D326) for helping the sample collection. Special thanks had to go to Dr. Matthew Patey, Dr. Duncan Purdie, Dr. Sebastian Steigenberger and Dr. Micha Rijkenberg for the permission of interpolating their data to complete this study.

\section{REFERENCES}

Baker, A.R., Jickells, T.D., Witt, M., \& Linge, K.L. (2006). Trends in the solubility of iron, aluminium, manganese and phosphorus in aerosol collected over the Atlantic Ocean. Marine Chemistry, 98: 43-58.

Baker, A.R., Weston, K., Kelly, S.D., Voss, M., Streu, P.S., \& Cape, J.N. (2007). Dry and wet deposition of nutrients from the tropical Atlantic atmosphere: Links to primary productivity and nitrogen fixation. Deep Sea Research Part I: Oceanographic Research Papers, 54(10): 17041720 .

Batten, M.L., Martinez, J.R., Bryan, D.W., \& Buch, E.J. (2000). A modelling study of the coastal eastern boundary current system off Iberia and Morocco. Journal of Geophysical Research, 105: 14173-14195.

Bergquist, B.A. \& Boyle, E.A. (2006). Dissolved iron in the tropical and subtropical Atlantic Ocean. Global Biogeochemical Cycles, 20.

Bucciarelli, E., Blain, S., \& Treguer, P. (2001). Iron and manganese in the wake of the Kerguelen Islands (Southern Ocean). Marine Chemistry, 73: 21-36.

Castrillejo, M., Statham, P.J., Fones, G.R., Planquette, H., Idrus, F.A., \& Roberts, K. (2013). Dissolved trace metals (Ni, Zn, Co, Cd, Pb, Al, and $\mathrm{Mn}$ ) around the Crozet Islands, Southern Ocean. Journal of Geophysical Research: Oceans, 118: 5188-5201.
Chase, Z., Johnson, K.S., Elrod, V.A., Plant, J.N., Fitzwater, S.E., Pickell, L., \& Sakamoto, C.M. (2005). Manganese and iron distributions off central California influenced by upwelling and shelf width. Marine Chemistry, 95: 235-254.

Chiapello, I., Bergametti, G., Gomes, L., Chatenet, B., Dulac, F., Pimenta, J., \& Suares, E.S. (1995). An additional low layer transport of Sahelian and Saharan dust over the North Eastern Tropical Atlantic. Geophysical Research Letters, 22: 3191 3194.

de Jong, J.T.M., Boye, M., Gelado-Caballero, M.D., Timmermans, K.R., Veldhuis, M.J.W., Nolting, R.F., van den Berg, C.M.G., \& de Baar, H.J.W. (2007). Inputs of iron, manganese and aluminium to surface waters of the Northeast Atlantic Ocean and the European continental shelf. Marine Chemistry, 107: 120-142.

Gordon, R.M., Johnson, K.S., \& Coale, K.H. (1998). The behaviour of iron and other trace elements during the IronEx-I and PlumEx experiments in the Equatorial Pacific. Deep-Sea Research Part IITopical Studies in Oceanography, 45: 995-1041.

Guieu, C., Loÿe-Pilot, M.-D., Ridame, C., \& Thomas, C. (2002). Chemical characterization of the Saharan dust end-member: some biogeochemical implications for the western Mediterranean Sea. Journal of Geophysical Research, 107D(15): 582.

Jickells, T.D. \& Spokes, L.J. (2001). Atmospheric iron inputs to the oceans. In Turner, D.R. \& Hunter, K.A. (Eds.), The biogeochemistry of iron in seawater. IUPAC Series on Analytical and Physical Chemistry of Environmental Systems. John Wiley \& Sons, LTD. Pp 85-122.

Johnson, J. \& Stevens, I. (2000), A fine resolution model of the eastern North Atlantic between the Azores, the Canary Islands and the Gibraltar Strait. Deep-Sea Research, 47: 875-899.

Laes, A., Blain, S., Laan, P., Ussher, S.J., Achterberg, E.P., Treguer, P., \& de Baar, H.J.W. (2007). Sources and transport of dissolved iron and manganese along the continental margin of the Bay of Biscay. Biogeosciences, 4: 181-194.

Luengen, A.C., Raimondi, P.T., \& Flegal, A.R. (2007). Contrasting biogeochemistry of six trace metals during the rise and decay of a spring phytoplankton bloom in San Francisco Bay. Limnology and Oceanography, 52: 1112-1130.

Measures, C.I. \& Vink, S. (2000). On the use of dissolved aluminium in surface waters to estimate dust deposition to the ocean. Global Biogeochemical Cycles, 14: 317-327.

Mendez, J., Guieu, C., \& Adkins, J. (2010). Atmospheric input of manganese and iron to the ocean: seawater dissolution experiments with Saharan and North American dusts. Marine Chemistry, 120: 34-43. 
Patey, M.P., Achterberg, E.P., Rijkenberg, M.J., \& Pearce, R. (2015). Aerosoltime-series measurements over the tropical Northeast Atlantic Ocean: Dust sources, elemental composition and mineralogy. Marine Chemistry, 174: 103-119.

Patey, M.D., Rijkenberg, M.J.A., Statham, P.J., Stinchcombe, M.C., Achterberg, E.P., \& Mowlem, M. (2008). Determination of nitrate and phosphate in seawater at nanomolar concentrations. Trac-Trends in Analytical Chemistry, 27(2): 169-182.

Patey, M.D. (2010). Trace metals and nutrients in aerosols over the tropical and subtropical North Atlantic Ocean. PhD Thesis. Southampton: University of Southampton. P 182.

Peterson, R.G., Stramma, L., \& Kortum, G. (1996). Early concepts and charts of ocean circulation. Progress in Oceanography, 37: 1115.

Rijkenberg, M.J.A., Steigenberger, S., Powell, C.F., van Haren, H., Patey, M.D., Baker, A.R., \& Achterberg, E. (2012). Fluxes and distribution of dissolved iron in the eastern (sub-) tropical North Atlantic Ocean. Global Biogeochemical Cycles, 26, GB3004.

Ruzicka, J. \& Hansen, E.H. (1988). Flow injection analysis in chemical analysis: a series of monographs on analytical chemistry and its applications. Flow Injection Analysis. Second Edition. New York, USA: Wiley \& Sons Inc.

Sarthou, G., Baker, A.R., Blain, S., Achterberg, E.P., Boyé, M., Bowie, A.R., Croot, P., Laan, P., De Baar, H.J.W., Jickells, T.D., \& Worsfold, P.J. (2003). Atmospheric iron deposition and seasurface concentrations in the eastern Atlantic Ocean. Deep-Sea Research I, 50: 1339-1352.
Seeyave, S., Lucas, M.I., Moore, C.M., \& Poulton, A.J. (2007). Phytoplankton productivity and community structure in the vicinity of the Crozet Plateau during austral summer 2004/2005. DeepSea Research Part II-Topical Studies in Oceanography, 54: 2020-2044.

Spokes, L., Jickells, T., \& Jarvis, K. (2001). Atmospheric inputs of trace metals to the northeast Atlantic Ocean: the importance of southeasterly flow. Marine Chemistry, 76: 319-330.

Statham, P.J. \& Burton, J.D. (1986). Dissolved manganese in the North-Atlantic Ocean, 0-35 degrees-N. Earth and Planetary Science Letters, 79: $55-65$.

Statham, P.J., Yeats, P.A., \& Landing, W.M. (1998). Manganese in the eastern Atlantic Ocean: processes influencing deep and surface water distributions. Marine Chemistry, 61: 55-68.

Stramma, L., Hüttl, S., \& Schafstall, J. (2005). Water masses and currents in the upper tropical northeast Atlantic off northwest Africa, Journal of Geophysical Research, 110: 1-14.

Sunda, W.G. \& Huntsman, S.A. (1983). Effect of competitive interactions between manganese and copper on cellular manganese and growth in estuarine and oceanic species of the diatom Thalassiosira. Limnology and Oceanography, 28: 924-934.

Wedepohl, K.H. (1995). The composition of the continental crust. Geochimica et Cosmochimica Acta, 59: 1217-1232.

Welschmeyer, N.A. (1994). Fluorometric analysis of chlorophyll- $a$ in the presence of chlorophyll- $b$ and pheopigments. Limnology and Oceanography, 39(8): 1985-1992.

Zhou, M., Paduan, J.D., \& Niiler, P.P. (2000). Surface currents in the Canary Basin from drifter observations. Journal of Geophysical Research: Oceans, 105(C9): 21893-21911. 